\title{
Prevalence of adhesions and associated postoperative complications after cesarean section in Ghana: a prospective cohort study
}

Mercy A. Nuamah ${ }^{1 *}$, Joyce L. Browne ${ }^{2 \dagger}$, Alexander V. Öry ${ }^{2}$, Nelson Damale ${ }^{1,3}$, Kerstin Klipstein-Grobusch 2,4 and Marcus J. Rijken ${ }^{2,5}$

\begin{abstract}
Background: The global increase in Cesarean section rate is associated with short- and long-term complications, including adhesions with potential serious maternal and fetal consequences. This study investigated the prevalence of adhesions and association between adhesions and postoperative complications in a tertiary referral hospital in Accra, Ghana.

Methods: In this prospective cohort study, 335 women scheduled for cesarean section at Korle-Bu Teaching Hospital in Accra, Ghana were included from June to December 2015. Presence or absence of adhesions was recorded and the severity of the adhesions was scored using a classification system. Associations between presence and severity of adhesions, postoperative complications, and maternal and infant outcomes at discharge and 6 weeks postpartum were assessed using multivariate logistic and linear regression analysis.

Results: Of the participating women, 128 (38\%) had adhesions and 207 (62\%) did not. Prevalence of adhesions increased with history of caesarean section; $2.8 \%$ with no CS but may have had an abdominal surgery, $51 \%$ with one previous CS, 62\% with $>1$ CS). Adhesions significantly increased operation time (mean $39.2( \pm 15.1)$ minutes, absolute adjusted difference with presence of adhesions $9.6 \mathrm{~min}, 95 \% \mathrm{Cl}$ 6.4-12.8), infant delivery time (mean $5.4( \pm 4.8)$ minutes, adjusted difference $2.4 \mathrm{~min}, 95 \% \mathrm{Cl} 1.3-3.4$ ), and blood loss for women with severe adhesions (mean blood loss $418.8 \mathrm{ml}$ $( \pm 140.6)$, adjusted difference $57.6 \mathrm{ml}(95 \% \mathrm{Cl} 12.1-103.0)$. No differences for other outcomes were observed.
\end{abstract}

Conclusion: With cesarean section rates rising globally, intra-abdominal adhesions occur more frequently. Risks of adhesions and associated complications should be considered in counseling patients for cesarean section.

Keywords: Cesarean sections, Adhesions, Complications, Low- and middle-income countries

\section{Plain English summary}

Cesarean sections (CS) are potentially life saving for mother and child. The percentage of babies born through CS is rising globally, including in low- and middle-income countries. As the procedure is not without risks or complications, it is important to understand how often these arise. Adhesion (scar tissue) formation

\footnotetext{
* Correspondence: manuamah@ug.edu.gh

${ }^{\dagger}$ Equal contributors

'Department of Obstetrics and Gynecology, School of Medicine and Dentistry, College of Health Sciences, University of Ghana, P.O. Box GP 4236, Accra, Ghana

Full list of author information is available at the end of the article
}

can happen after any abdominal surgery and occurs often after a CS. A major problem is that adhesions make (future) CS more difficult.

What did we study? We observed CS of 335 women in in Korle-Bu Teaching Hospital (KBTH), a large referral hospital in Accra, Ghana. We recorded whether adhesions were present, how severe they were, and whether they were associated with risks for mother or baby.

What did we find out? Over a third of women $(38 \%)$ had adhesions, and this occurred more often if they had had a previous CS or abdominal surgery: about twothird of women with more than one CS had adhesions. 
The surgeries of women who had adhesions were on average longer (by $9.6 \mathrm{~min}$ ), the time until the baby was born was longer (2.4 $\mathrm{min})$, and women with severe adhesions had more blood loss $(57 \mathrm{ml})$. No differences for other outcomes for mother or baby were observed.

What do we conclude from these findings? A CS can result in post-operative complications such as adhesions. These have implications for future pregnancies: adhesions result in longer duration of repeat CS and more blood loss. Given the rise in CS and their associated complications, it is important to avoid unnecessary CS.

\section{Background}

Cesarean section (CS) is the most frequently performed operation worldwide and the rates of CS delivery have been rising rapidly over the past few decades [1-3]. Currently, the long standing World Health Organization (WHO) advice of $10-15 \%$ of deliveries by CS [4] or the recently suggested optimum of $19 \%$ [5] is exceeded in many high-income (average rate of 27\%) and low to middle income settings (between $3 \%$ to $29 \%$ ) [3, 6-8]. This increase has been attributed to improved safety of the procedure, fewer vaginal births after cesarean (VBAC), preferred method of delivery in breech presentation or suspected cephalopelvic disproportion, more highrisk pregnancies, an increase in CS performed at maternal request, the medicolegal environment of obstetrics, and changes in practice patterns of providers [9-11].

The prevalence of CS-associated short- and long-term complications increases with each additional CS and these include postoperative bleeding and infection, abdominal adhesions, placenta accreta and surgical injury $[9,12,13]$. In addition, future pregnancies may be complicated by uterine scar rupture with potential serious maternal and fetal consequences [14].

Adhesions are reported as a frequent complication of CS [12], and can result in abdominal discomfort, pain and associated lower quality of life [15]. In the long term, adhesions may complicate future CS because of increased difficulty of the surgical procedure resulting in complications such as bladder damage and prolonged duration of surgery [16]. Especially with an emergency (repeat) CS, these often unexpected difficulties can result in adverse perinatal and maternal outcomes such as birth asphyxia and maternal exhaustion. Despite the increases in (repeat) CS, few studies exist on the prevalence of adhesions and associated maternal and perinatal outcomes, especially in Sub-Saharan African settings.

\section{Methods}

\section{Aims}

This study aimed to investigate the prevalence of adhesions in women with and without previous CS, and the association between adhesions and maternal and neonatal outcomes 3 days and 6 weeks postpartum.

\section{Study design and setting}

This prospective cohort study was conducted between June and December 2015 at the Korle $\mathrm{Bu}$ Teaching Hospital (KBTH); a tertiary referral hospital in Accra, Ghana. KBTH has between 10.500-11.000 deliveries annually and a CS rate of 43\% in 2013 (unpublished data, annual statistics report KBTH 2013), more than Ghana's average of $4 \%$ in 2003 [2].

\section{Participants}

All women $>18$ years of age admitted for elective or emergency CS were eligible candidates. Recruitment primarily took place on weekdays from 9:00 to 17:00, based on labor ward coverage by research assistants. All participants were followed until discharge from the hospital, usually 3 days postpartum. A subset of women and infants recruited during the first 5 weeks of the study were evaluated at 6 weeks during their routine postnatal appointment. Reporting was according to STROBE guidelines [17].

\section{Sample size calculation}

The sample size was calculated based on an estimated proportion of women undergoing a repeat CS of 30\% and the assumption that adhesions were present in most of the repeat CS women, but not primary CS women [12].

To detect a significant difference $(p<0.05)$ in adhesion prevalence between women with primary versus repeat CS with a z-score of 1.96 and a power of 95\% (2tailed alpha $=0.05), 322$ participants were required [18]. To account for a $10 \%$ contingency, 350 women were to be included.

\section{Variables}

Trained research assistants collected data using standardized questionnaires. Pre-operatively, demographic and socio-economic data (age, marital status, education level) was collected. Medical and obstetric history was obtained from the patients' maternity booklets, labor ward records and doctors notes and included the following: gestational age at delivery (based on ultrasound gestational age determination in first trimester or at booking, known medical conditions including presence of fibroids, use of medication (and type), mid-pregnancy weight, previous hospital admittances and/or surgeries, number of previous pregnancies and deliveries including abortions and miscarriages, any problems during previous pregnancies or deliveries as well as during the current pregnancy, indication for and number of previous cesarean sections and the duration and location of hospital stay after the most recent CS. Indication for CS 
was classified as maternal, combined maternal/neonatal or neonatal. Maternal reasons included: antepartum hemorrhage, large fibroid in situ obstructing vaginal delivery, previous CS, (pre)-eclampsia, complicated obstetric history (e.g. perinatal death), maternal wish and gestational diabetes (ketoacidosis). Combined maternal/neonatal included: cephalopelvic disproportion (CPD), placenta previa, unsuccessful VBAC, and estimated birth weight $>4000$ g. Neonatal indications were breech presentation, fetal distress, twin pregnancy, premature rupture of membranes (PROM), and severe oligohydramnion.

\section{Exposure variable}

Presence of adhesions was established during CS by the operating gynecologist or resident, and assessed by two research assistants trained in adhesion scoring (Table 1) using the adhesion classification scheme developed by Tulandi \& Lyell [17]. In this scheme, adhesion is graded by location, consistency and size. Filmy (transparent and easily dehisced) adhesions larger than $6 \mathrm{~cm}$ wide were allotted maximum of 4 points whereas dense (difficult to separate) adhesions were allotted minimum of $4(<3 \mathrm{~cm})$ and maximum of $16(>6 \mathrm{~cm})$ points if they occurred between the uterus and bladder, abdominal facial or omentum. Irrespective of size, a filmy adhesion between omentum and abdominal facial was allotted 2 points, and a dense adhesion 8 points. With respect to other pelvic structures that interfere with delivery, filmy and dense adhesions were graded with 4 and 8 points, respectively. Severity of adhesion was dichotomized as absent or present, and classified as "mild" or "severe" based on adhesion scores below and above the median (16 points, range $0-64$ points).

Table 1 Adhesion classification system according to Tulandi \& Lyell [17]

\begin{tabular}{lllll}
\hline Adhesions & $\begin{array}{l}\text { Consistency } \\
\text { of adhesions }\end{array}$ & $<3 \mathrm{~cm}$ & $3-6 \mathrm{~cm}$ & $>6 \mathrm{~cm}$ \\
\hline $\begin{array}{l}\text { Between uterus and } \\
\text { bladder }\end{array}$ & Filmy & 1 & 2 & 4 \\
$\begin{array}{l}\text { Between uterus and } \\
\text { abdominal fascia }\end{array}$ & Dense & 4 & 8 & 16 \\
$\begin{array}{l}\text { Between uterus and } \\
\text { omentum }\end{array}$ & Dense & 4 & 8 & 16 \\
$\begin{array}{l}\text { Between omentum and } \\
\text { abdominal fascia }\end{array}$ & Filmy & 1 & 2 & 4 \\
$\begin{array}{l}\text { Adhesions to other pelvic } \\
\text { structures that interfere with } \\
\text { the delivery }\end{array}$ & Filmy & 4 & 8 & 16 \\
\hline
\end{tabular}

\section{Outcome variables}

Perioperative outcomes obtained were operation time (measured from skin incision to skin closure), infant delivery time (incision until time of birth), perioperative blood loss, Apgar scores at $5 \mathrm{~min}(<7$ or $\geq 7)$, and need for neonatal intensive care unit (NICU) admission.

Postpartum outcomes until discharge collected were the length of the hospital stay and occurrence of wound infection. Information during their 6 weeks postpartum follow up visit collected was: occurrence of fever or wound infection, need for (continued) use of painkillers, abnormal bleeding (persistent spotting or bleeding clots as determined by attending clinician), ability to resume daily activities, and the need for a healthcare

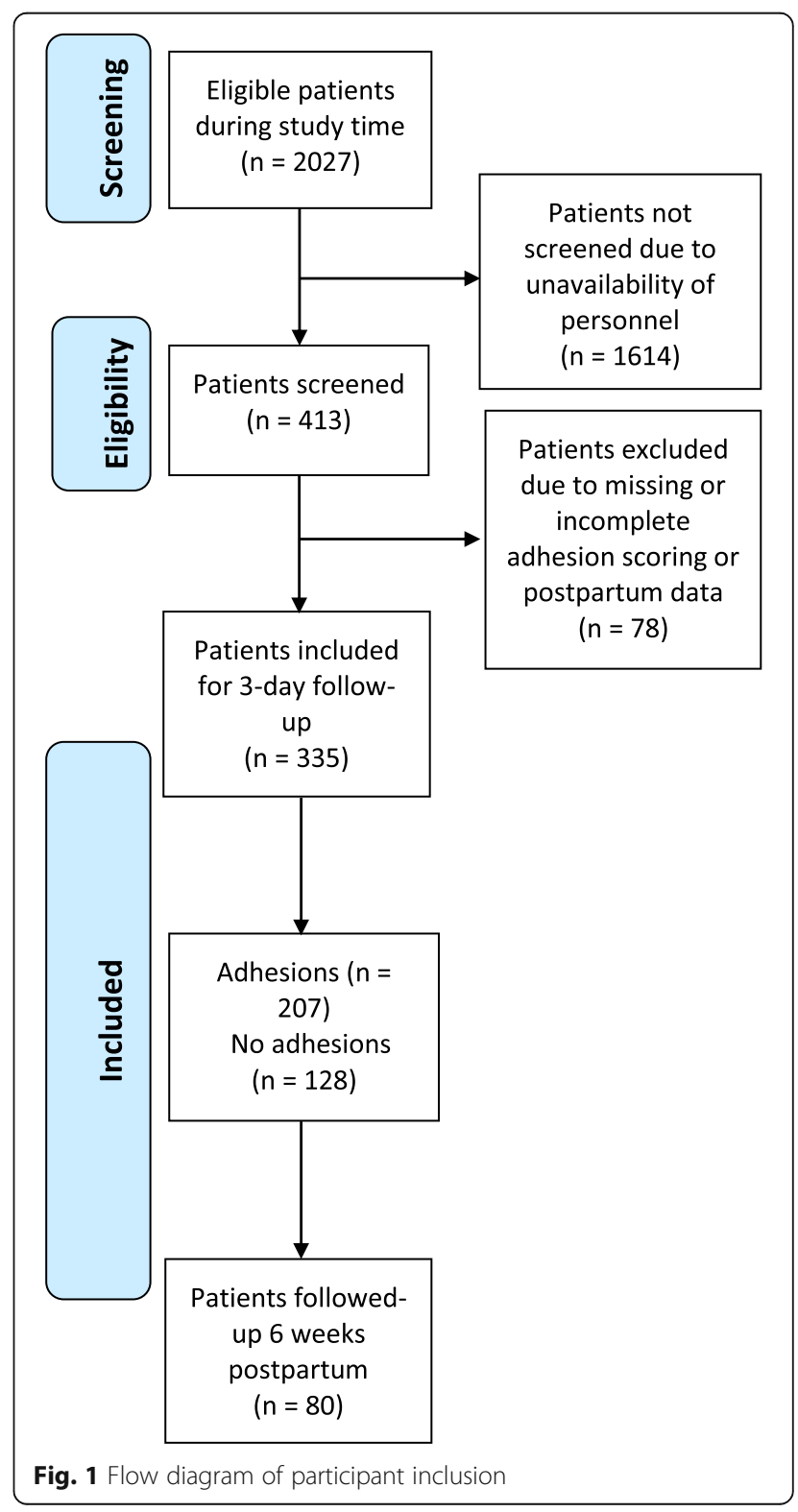


professional consultation in the 6 weeks postpartum for mother and /or her infant.

\section{Statistical analysis}

Baseline characteristics were presented for all participants with means and standard deviations for continuous variables, and frequency and percentage for categorical variables. To compare women with and without adhesions, baseline characteristics differences were assessed using Student's T-tests, Fisher's exact tests, Pearson's Chi square or one-way ANOVA, where appropriate.

The association between adhesions and postoperative and postpartum outcomes was assessed using logistic and linear regression analyses. Continuous outcomes were presented as absolute differences with 95\% confidence interval (95\% CI), dichotomous outcomes as Odds ratios (ORs) with $95 \% \mathrm{CI}$.

Two confounders were selected for inclusion in the multivariate regression analysis based on known associations with the determinants and outcomes: weight at 20 weeks gestation and presence of uterine fibroids. Values for confounders with $>15 \%$ incomplete data were imputed using multiple imputations. Missing outcome data were considered lost at random and excluded for analysis.

Post-hoc analyses to explore the relationship between adhesion severity and outcomes were performed in a similar regression approach, but with adhesions as a continuous score and by the classifications of mild and severe.

The level of statistical significance determined at $p<0.05$. All statistical analyses were performed with STATA (Version 11, StataCorp, College Station, Texas).

\section{Results}

Between June and December 2015, 413 participants were included in the study, $20.4 \%$ of the 2027 cesarean deliveries performed at Korle $\mathrm{Bu}$ Teaching Hospital in this period. Seventy-eight patients were excluded due to missing or incomplete data on adhesion score or postpartum outcomes, resulting in a total of 335 women included for analysis (81.1\%) (Fig. 1). All included patients were followed-up until discharge, and 80 women (23.8\%) were followed up 6 weeks postpartum.

\section{Prevalence and severity of adhesions}

Of the 335 included women, 207 (62\%) did not have adhesions and 128 (38\%) did. Prevalence of adhesions increased with history of caesarean section ( $0 \%$ with no history of CS or abdominal surgery, 2.8\% (3/107) with no history of CS but may have had a previous abdominal surgery, $51 \%(77 / 150)$ of women who had one previous CS, and $62 \%(48 / 78)$ of those with two or more CS (Fig. 2, Additional file 1: Table S1).

In Table 2 the baseline socio-demographic, obstetric and health characteristics by presence or absence of adhesions (Additional file 2: Table S2 by adhesion category) are presented. Women with adhesions were significantly older $(32.3 \pm 4.3$ vs. $30.6 \pm 5.2$ years) and less likely to live in the Greater Accra region (107/125, 85.6\% vs.191/206, 92.7\%). Women with adhesions more often were multiparous (125/127, 98.4\% vs.144/207, 69.6\%), and had a previous CS (125/128, 97.7\% vs.103/207, 49.8\%). Seventeen women had a previous abdominal surgery other than CS, all in the adhesions group $(17 / 128,13.3 \%)$ Women with adhesions were more likely to currently have an elective CS (59/128, $46.1 \%$ vs. $68 / 207,32.9 \%)$ on maternal indication $(89 / 126$,

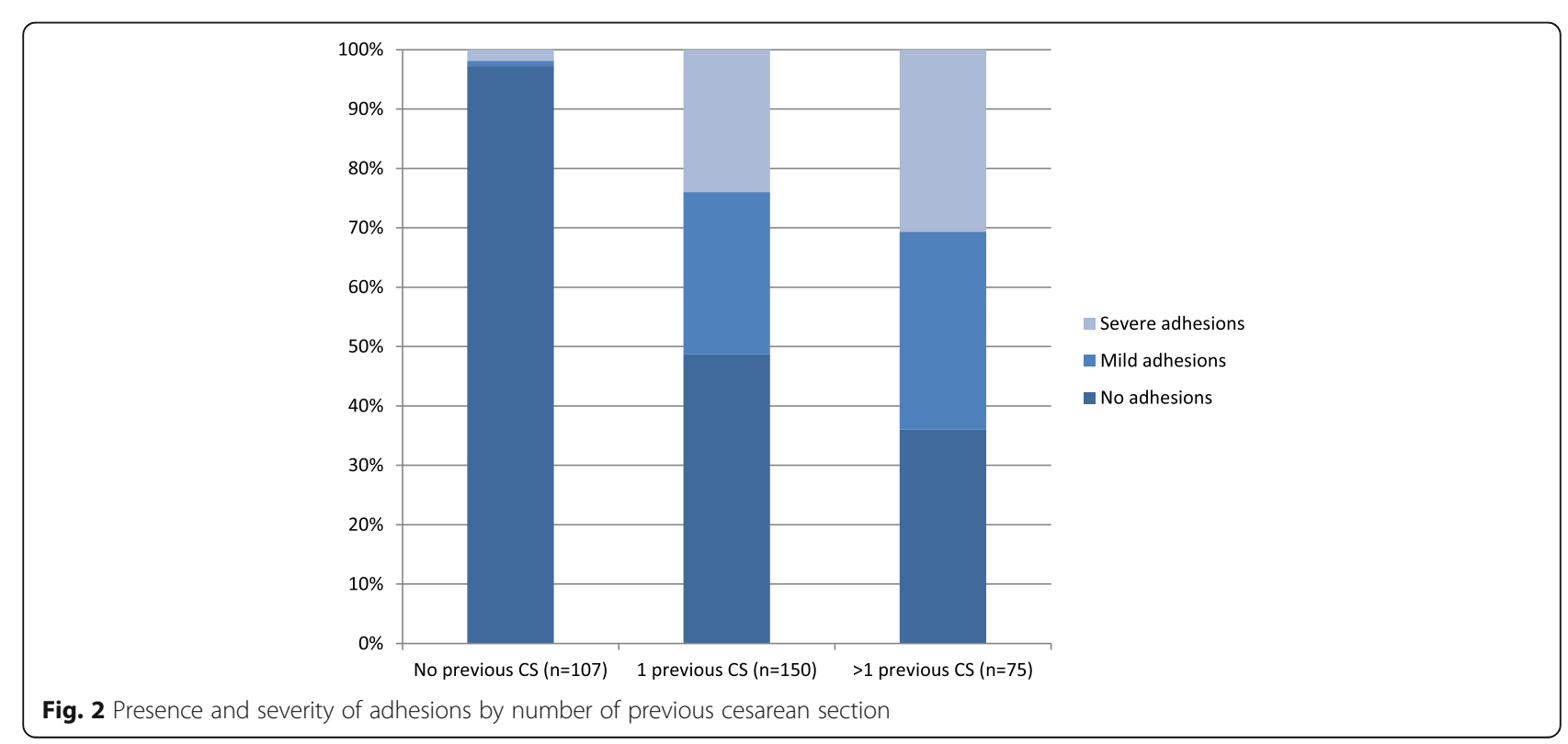


Table 2 Baseline characteristics of participating women

\begin{tabular}{|c|c|c|c|c|}
\hline & All, $n=335$ & No adhesions, $n=207$ & Adhesions, $n=128$ & $P$-value \\
\hline \multicolumn{5}{|l|}{ Socio-demographic characteristics } \\
\hline Age (years) & $31.2 \pm 4.9$ & $30.6 \pm 5.2$ & $32.3 \pm 4.3$ & $<0.01$ \\
\hline Current living in Greater Accra region (n, \%) & $298(90.0)$ & $191(92.7)$ & $107(85.6)$ & $<0.01$ \\
\hline Married, engaged or living together (n, \%) & $286(87.2)$ & $174(87.0)$ & $112(87.5)$ & 0.90 \\
\hline Education level (n, \%) & & & & 0.99 \\
\hline No education & $28(8.5)$ & $17(8.4)$ & $11(8.6)$ & \\
\hline Primary school & $94(28.5)$ & $59(29.1)$ & $35(27.6)$ & \\
\hline Secondary school & $113(34.2)$ & $69(34.0)$ & $44(34.7)$ & \\
\hline Tertiary school & $95(28.8)$ & $58(28.6)$ & $37(29.1)$ & \\
\hline \multicolumn{5}{|l|}{ Obstetric and medical history } \\
\hline Parity $(n, \%)$ & & & & $<0.01$ \\
\hline 0 & $65(19.5)$ & $63(30.4)$ & $2(1.6)$ & \\
\hline $1-4$ & $259(77.5)$ & $137(66.2)$ & $122(96.1)$ & \\
\hline $5-9$ & $10(3.0)$ & $7(3.4)$ & $3(2.4)$ & \\
\hline Number of previous CS (n, \%) & & & & $<0.01$ \\
\hline 0 & 107 (31.9) & $104(50.2)$ & $3(2.3)$ & \\
\hline 1 & $150(44.8)$ & $73(35.3)$ & $77(60.2)$ & \\
\hline 2 & $61(18.2)$ & $27(13.0)$ & $34(26.6)$ & \\
\hline 3 & $17(5.1)$ & $3(1.5)$ & $14(10.9)$ & \\
\hline Indication for previous CS (n, \%) & & & & 0.07 \\
\hline Maternal & $61(28.9)$ & $21(21.4)$ & $40(35.4)$ & \\
\hline Maternal-neonatal & $82(38.9)$ & $40(40.8)$ & $42(37.2)$ & \\
\hline Neonatal & $68(32.2)$ & $37(37.8)$ & $31(27.4)$ & \\
\hline Previous surgery (n, \%) & $17(5.1)$ & $0(0)$ & $17(13.3)$ & $<0.01$ \\
\hline Uterine fibroids & $12(3.6)$ & $6(2.9)$ & $6(4.7)$ & 0.39 \\
\hline Mid-pregnancy weight in kg (mean, SD) & $74.2(14.5)$ & $73.8(15.0)$ & $75.0(13.3)$ & 0.49 \\
\hline \multicolumn{5}{|l|}{ Current delivery } \\
\hline Gestational age at delivery in weeks $(n, \%)$ & & & & 0.62 \\
\hline$\leq 37$ & $78(25.4)$ & $51(27.1)$ & $27(22.7)$ & \\
\hline $38-41$ & $220(71.7)$ & $130(69.7)$ & 89 (74.8) & \\
\hline$\geq 42$ & $9(2.9)$ & $6(3.2)$ & $3(2.5)$ & \\
\hline Type of current CS & & & & 0.02 \\
\hline Elective & $127(37.9)$ & $68(32.9)$ & $59(46.1)$ & \\
\hline Emergency & $208(62.1)$ & $139(67.2)$ & $69(53.9)$ & \\
\hline Indication for current CS (n, \%) & & & & $<0.01$ \\
\hline Maternal & $173(52.9)$ & $84(41.8)$ & 89 (70.6) & \\
\hline Maternal-neonatal & $83(25.4)$ & $57(28.4)$ & $26(20.6)$ & \\
\hline Neonatal & $71(21.7)$ & $60(29.9)$ & $11(8.7)$ & \\
\hline
\end{tabular}

CS cesarean section, $n$ number, SD standard deviation

$70.6 \%$ vs. $84 / 203,41.3 \%)$. Women did not differ in education, marital status, mid-pregnancy weight, present of uterine fibroids or indication of current CS. The prevalence and severity of adhesions increased with each additional CS (Fig. 2).

\section{Association between adhesions and complications}

Presence of adhesions significantly increased the operation time (mean duration $39.2( \pm 15.1)$ minutes, absolute adjusted difference with presence of adhesions $9.6 \mathrm{~min}$ (95\% CI 6.4-12.8) and $14.2 \mathrm{~min}$ (95\% CI 10.1-18.3) for 
severe adhesions). Infant delivery time was on average 5.4 $( \pm 4.8)$ minutes, the adjusted difference $2.4 \mathrm{~min}(95 \% \mathrm{CI}$ 1.3-3.4) with presence of adhesions and $3.1 \mathrm{~min}$ (95\% CI 1.7-4.4) for severe adhesions) compared to no adhesions (Tables 3 and 4, Additional file 3: Table S3). Blood loss was not-significantly higher for women with adhesions, but for women with severe adhesions there was significantly more peri-operative blood loss recorded (mean blood loss $418.8( \pm 140.6) \mathrm{ml}$, adjusted difference $57.6 \mathrm{ml}$ (12.1-103.0) for severe adhesions). No differences for other perioperative or postpartum maternal and neonatal outcomes were observed (Tables 3 and 4).

\section{Discussion}

This study observed that the majority of women with a history of CS or abdominal surgery had adhesions, and this affected operation time, infant delivery time, and perioperative blood loss (for severe adhesions), but not other outcomes. The prevalence and severity of adhesions increased with each additional repeat CS.

These findings concur with earlier studies that found adhesions to be a frequent complication after CS $[9,12$, 13, 17-22]. The prevalence of adhesions in this population in Ghana is higher than reported in previous studies
[12]. This could be a reflection of a higher prevalence of complex cases at a major referral teaching hospital in this region, which may also explain the high rate of CS conducted at $\mathrm{KBTH}$ (43\% of deliveries). Alternatively, the prevalence of post operative adhesions in low and middle-income countries may be higher as the performance of a surgical procedure is subject to adequately trained medical personnel, available infrastructure and access to resources [18, 23-26]. Therefore, and reinforced by the increase in CS rates, there is an urgent need for data of post operative complications such as adhesions from low and middle income countries. Such prospective studies should include detailed information of procedures and complications during the first CS.

We observed primarily perioperative consequences of adhesions. These factors such as total operation time and infant delivery time can have clinical consequences at time of emergency procedures due to fetal or maternal distress. Further, even in non-emergency situations, increased operation time requires prolonged anesthesia [27] and exposure to infection risk [28]. The increase in blood loss with (severe) adhesions is relevant in light of the persistent high prevalence of anemia in pregnant women in low- and middle income country settings [29].

Table 3 Maternal and neonatal outcomes in women, by adhesion status

\begin{tabular}{|c|c|c|c|c|}
\hline & All & No adhesions & Adhesions & $P$ - value \\
\hline & $n=335$ & $n=207$ & $n=128$ & \\
\hline \multicolumn{5}{|l|}{ Maternal outcomes } \\
\hline \multicolumn{5}{|l|}{ Perioperative outcomes $(n=335)$} \\
\hline Operation time (minutes), mean, SD & $39.2(15.1)$ & $35.4(13.7)$ & $45.3(15.2)$ & $<0.01$ \\
\hline Infant delivery time (minutes), mean, SD & $5.4(4.8)$ & $4.5(4.5)$ & $6.9(4.8)$ & $<0.01$ \\
\hline Perioperative blood loss (ml), mean, SD & $418.8(140.6)$ & $408.5(167.6)$ & 434.8(140.5) & 0.14 \\
\hline \multicolumn{5}{|c|}{ Postoperative outcomes at time of discharge $(n=335)$} \\
\hline Length of hospital stay (days), mean, SD & $3.8(1.0)$ & $3.9(0.9)$ & $3.7(1.1)$ & 0.17 \\
\hline Wound infection (n, \%) & $4(1.2)$ & $4(2.0)$ & $0(0.0)$ & 0.30 \\
\hline \multicolumn{5}{|l|}{6 weeks postpartum $(n=80)$} \\
\hline Fever $(n, \%)$ & $4(5.0)$ & $2(4.7)$ & $2(5.4)$ & 1.00 \\
\hline Wound infection (n, \%) & $8(7.6)$ & $4(6.6)$ & $4(8.9)$ & 0.72 \\
\hline Use of painkillers (n, \%) & $3(3.7)$ & $1(2.3)$ & $2(5.4)$ & 0.59 \\
\hline Resume daily activities (n, \%) & $56(70.0)$ & $31(72.1)$ & $25(67.6)$ & 0.66 \\
\hline Abnormal bleeding $(\mathrm{n}, \%)$ & $10(12.5)$ & $5(11.6)$ & $5(13.5)$ & 0.80 \\
\hline Need for healthcare professional (n, \%) & $12(15.0)$ & $8(18.6)$ & $4(10.8)$ & 0.37 \\
\hline \multicolumn{5}{|l|}{ Neonatal outcomes } \\
\hline \multicolumn{5}{|l|}{ Perioperative outcomes $(n=335)$} \\
\hline Apgar score $<7$ at 5 min. $(n, \%)$ & $20(6.0)$ & $13(6.3)$ & $7(5.5)$ & 0.75 \\
\hline NICU admissions (n, \%) & $42(13.4)$ & $28(14.7)$ & $14(11.4)$ & 0.25 \\
\hline \multicolumn{5}{|l|}{6 weeks postpartum $(n=80)$} \\
\hline Need for healthcare professional (n, \%) & $4(5.0)$ & $1(2.3)$ & $3(8.1)$ & 0.33 \\
\hline
\end{tabular}


Table 4 Association between adhesions and maternal and neonatal outcomes

\begin{tabular}{|c|c|c|c|}
\hline Maternal outcomes & No adhesions $n=207$ & $\begin{array}{l}\text { Adhesions } \\
n=124\end{array}$ & \\
\hline & & Unadjusted $\beta(95 \% \mathrm{Cl})$ & Adjusted $\beta(95 \% \mathrm{Cl})^{\mathrm{a}}$ \\
\hline \multicolumn{4}{|l|}{ Maternal outcomes } \\
\hline \multicolumn{4}{|l|}{ Perioperative outcomes $(n=335)$} \\
\hline Operation time (minutes) & Ref & $9.81(6.60-13.01)$ & $9.58(6.39-12.77)$ \\
\hline Infant delivery time (minutes) & Ref & $2.36(1.32-3.41)$ & $2.35(1.29-3.39)$ \\
\hline Perioperative blood loss (ml) & Ref & $26.30(-9.08-61.68)$ & $22.69(-12.34-57.73)$ \\
\hline \multicolumn{4}{|c|}{ Postoperative outcomes at discharge $(n=335)$} \\
\hline Length of hospital stay (days) & Ref & $-0.15(-0.37-0.07)$ & $-0.15(-0.37-0.07)$ \\
\hline 6 weeks postpartum $(n=80)$ & & OR $(95 \% \mathrm{Cl})$ & aOR $(95 \% \mathrm{Cl})$ \\
\hline Fever & Ref & $1.17(0.16-8.75)$ & $1.68(0.15-9.00)$ \\
\hline Wound infection & Ref & $1.39(0.32-5.88)$ & $1.38(0.32-5.96)$ \\
\hline Daily use of painkiller & Ref & $2.40(0.21-27.59)$ & $2.30(0.20-26.49)$ \\
\hline Able to resume daily activities & Ref & $1.24(0.48-3.23)$ & $1.19(0.44-3.16)$ \\
\hline Abnormal bleeding & Ref & $1.18(0.32-4.47)$ & $1.16(0.30-4.44)$ \\
\hline Need for healthcare professional & Ref & $0.53(0.15-1.93)$ & $0.59(0.16-2.23)$ \\
\hline \multicolumn{4}{|c|}{ Neonatal outcomes Perioperative $(n=335)$} \\
\hline Apgar score at 5 min $<7$ & Ref & $1.16(0.45-2.98)$ & $1.18(0.45-3.08)$ \\
\hline NICU admission & Ref & $0.47(0.16-1.40)$ & $0.46(0.15-1.38)$ \\
\hline \multicolumn{4}{|l|}{6 weeks postpartum $(n=80)$} \\
\hline Need for healthcare professional & Ref & $3.71(0.36-37.26)$ & $4.55(0.37-55.05)$ \\
\hline
\end{tabular}

${ }^{\mathrm{a}}$ Adjusted for maternal weight at 20 weeks gestation and presence of uterine fibroids. NICU = neonatal intensive care unit

\section{Strengths and limitations}

Strengths of this study include the prospective design in which women were recruited before CS. The nested sub-study included women at 6 weeks postpartum and this allowed to not only assess perioperative outcomes, but explore important maternal and neonatal short and mid-term outcomes as postpartum blood loss, sepsis, wound infection, and postpartum need for a healthcare professional as well. Another strength of this study is the use of a standardized adhesion classification system, making it possible to quantify the presence and severity of adhesions in a systematic manner.

A number of limitations need to be considered in the interpretation of the data. First, because the research staff could not be present 24 h, 7 days a week at the facility, $20 \%$ of the eligible study base was included. This could have introduced selection bias, with more elective cases included potentially resulting in in higher operation and infant delivery times, but an underestimation of poor maternal and neonatal outcomes. Another limitation of the design of our study is the size of the 6 weeks postpartum follow-up group $(n=80)$, which could contribute to a lack of power to observe a difference in outcomes. Women followed up at 6 weeks were different in education level, more often had a neonatal indication for CS, and were more likely to have an elective CS (data not shown), possibly limiting generalizability of these findings. In busy obstetric settings such as KBTH including additional research visits create a lot of extra work pressure for the staff in limited available workspace. We expected the follow up of women 6 weeks post-partum to involve quite some additional efforts for the research team and therefore we planned to limit the follow up to the first 5 weeks of the study. However we could have ensured active follow up throughout the whole study, as there was generally a high follow up rate at six-week postpartum. For future studies we will include postpartum follow up for all women, or women could be followed by phone or home visits. A third limitation was the occurrence of missing data records for 79 participants initially enrolled. Because we assume this occurred randomly, and this was $<20 \%$ of the population, we do not expect this to strongly affected the study outcomes. Fourth, as this study was powered for the incidence of adhesions, and not other complications, sample size limitations could have contributed to the lack of significant findings for other complications. Finally, details on previous CS indication or surgical techniques were often lacking - reflective of the setting where this study took place: a major referral hospital in a low resources setting that received patients from most part of the country without detailed description of previous surgery history available. Future research could address some limitations in 
prospective cohorts starting at the first CS that follow pregnant women up until future pregnancies. Future studies could also investigate factors affecting the occurrence of adhesions including surgical techniques, and strategies to prevent the development of adhesions and other complications - as explored in the CORONIS studies [28-31].

\section{Implication for clinical practice}

Unfortunately, there is no gold standard to avoid adhesions or detect adhesions prior to surgery [16]. Surgical training, careful removal of debris and blood, and reducing the risk of infections will all contributes to reduced incidence [16, 32]. The use of barriers, peritoneal suturing, as well as various other closure techniques have not resulted in satisfactory reduction of adhesions occurrence [33, 34]. Therefore, pregnant women need to be carefully counseled about their options and associated implications, especially before and during the first pregnancy after their first CS to consider a vaginal birth after cesarean section (VBAC) or when requesting a CS for non-medical indication.

\section{Conclusion}

The majority of women with a history of CS or abdominal surgery had adhesions and this affected operation time, infant delivery time, and perioperative blood loss (for severe adhesions), but not other outcomes. With each additional repeat CS, prevalence and severity of adhesions increased. With the global increase in cesarean sections in general and particularly repeat cesareans, short- and long-term consequences will need to be considered and discussed with pregnant women during preoperative counseling. Notwithstanding the need for all people to have access to high quality safe surgical care [35], there is the concurrent responsibility to avoid unnecessary first cesarean sections [8].

\section{Additional files}

Additional file 1: Table S1. Presence and severity of adhesions by number of previous cesarean section. (DOCX $10 \mathrm{~kb}$ )

Additional file 2: Table S2. Baseline characteristics of participating women by adhesion group. (DOCX $14 \mathrm{~kb}$ )

Additional file 3: Table S3. Associations of adhesion groups by score and classification. (DOCX $15 \mathrm{~kb}$ )

\section{Abbreviations}

ANOVA: Analysis of variance; CS: Cesarean section; KBTH: Korle Bu Teaching Hospital; NICU: Neonatal intensive care unit; ORs: Odds ratios; STROBE: STrengthening the Reporting of OBservational studies in Epidemiology; VBAC: Vaginal births after cesarean; WHO: World Health Organization

\section{Acknowledgements}

The authors wish to acknowledge Gabriel Nuamah, obstetricians, residents, house officers and nurses at KBTH for their technical assistance. We are grateful for the advice of Prof. Tulandi about the adhesion score and Dr. John the Baptist Wilson for his feedback on the draft manuscript. We would like to express our appreciation to Dr. Peter Zuithoff for his statistical advice. We thank the pregnant women for their participation. Last but not the least, the authors wish to acknowledge the significant contribution of Dr. Samuel Amenyi Obed, the immediate former head of department of Obstetrics and Gynecology, whose sudden demise prevented him from participating in the project to the end.

Funding

Not applicable.

\section{Availability of data and materials}

The hard copies and electronic data set are available from the corresponding author on reasonable request.

\section{Authors' contributions}

MAN was responsible for correspondences and supervised data collection, co-designed the study and study procedures. JLB analyzed data, supported by MJR, MAN and AVÖ; and co-designed the study and study procedures. AVÖ designed the questionnaire and did the recordings during the CS. ND proposed the study and coordinated it. KK-G supported proposal and manuscript writing. MJR participated in questionnaire and standing operating procedure design, and data analysis. MAN, JLB, AVÖ and MJR drafted the first version of the manuscript. All authors participated in manuscript writing, read and approved of final manuscript.

\section{Authors' information}

Mercy A Nuamah, MD PhD is the research coordinator of the OBGYN department School of Medicine and Dentistry, University of Ghana. Joyce $L$ Browne, MD PhD is an epidemiologist and Assistant Professor of Global Health at Julius Global Health, Julius Center, UMC Utrecht.

Alexander V Öry, MD; is a family medicine trainee at the Julius Center, UMC Utrecht.

Nelson Damale, MBBS FACS, is a consultant obstetrician/gynecologist at Korle-Bu Teaching Hospital and senior lecturer at the School of Medicine and Dentistry, University of Ghana.

Kerstin Klipstein-Grobusch, PhD is an epidemiologist and associate professor of Global Health at Julius Global Health, Julius Center, UMC Utrecht and Visiting Associate Professor of Epidemiology at the School of Public Health, University of the Witwatersrand, South Africa.

Marcus J Rijken, MD PhD, is a final-year resident in Obstetrics \& Gynecology at the UMC Utrecht, and Assistant Professor of Global Health at Julius Global Health, Julius Center, UMC Utrecht.

\section{Ethics approval and consent to participate}

Approval of the Ethical and Protocol Review Committee of the College of Health Sciences, University of Ghana, was obtained for this study under protocol identification number CHS-Et/M.10 - P3.3/2014-2015. All participants provided written informed consent.

Consent for publication

Not applicable.

\section{Competing interest}

The authors declare that they have no competing interest.

\section{Publisher's Note}

Springer Nature remains neutral with regard to jurisdictional claims in published maps and institutional affiliations.

\section{Author details}

${ }^{1}$ Department of Obstetrics and Gynecology, School of Medicine and Dentistry, College of Health Sciences, University of Ghana, P.O. Box GP 4236, Accra, Ghana. ${ }^{2}$ University Medical Center Utrecht, Utrecht, The Netherlands. ${ }^{3}$ Department of Obstetrics and Gynecology, Korle-Bu Teaching Hospital, Accra, Ghana. ${ }^{4}$ Division of Epidemiology \& Biostatistics, School of Public Health, Faculty of Health Sciences, University of the Witwatersrand, Johannesburg, South Africa. ${ }^{5}$ Department of Obstetrics and Gynecology, Division of Woman and Baby, University Medical Center Utrecht, Utrecht, The Netherlands. 
Received: 21 June 2017 Accepted: 25 September 2017

Published online: 02 November 2017

\section{References}

1. Betran AP, Torloni MR, Zhang J, Ye J, Mikolajczyk R, Deneux-Tharaux C, et al. What is the optimal rate of caesarean section at population level? A systematic review of ecologic studies. Reprod Health. 2015;12:57.

2. Ronsmans C, Holtz S, Stanton C. Socioeconomic differentials in caesarean rates in developing countries: a retrospective analysis. Lancet. 2006;368: 1516-23.

3. Betrán AP, Merialdi M, Lauer JA, Bing-Shun W, Thomas J, Van Look P, et al. Rates of caesarean section: analysis of global, regional and national estimates. Paediatr Perinat Epidemiol. 2007;21:98-113.

4. Betran AP, Torloni MR, Zhang J, et al. WHO Statement on Caesarean Section Rates. Geneva, 2015. BJOG. 2016;123;667-70.

5. Molina G, Weiser TG, Lipsitz SR, Esquivel MM, Uribe-Leitz T, Azad T, et al. Relationship Between Cesarean Delivery Rate and Maternal and Neonatal Mortality. JAMA. 2015;314:2263.

6. Cavallaro FL, Cresswell JA, França GV, Victora CG, Barros AJ, Ronsmans C. Trends in caesarean delivery by country and wealth quintile: cross-sectional surveys in southern Asia and sub-Saharan Africa. Bull World Health Organ. 2013;91:914-922D

7. Temmerman M. Caesarean section surgical techniques: all equally safe. Lancet. 2016;388(10039):8-9.

8. Rijken MJ, Meguid T, van den Akker T, van Roosmalen J, Stekelenburg J. Global surgery and the dilemma for obstetricians. Lancet. 2015:386:1941-2.

9. Marshall NE, Fu R, Guise J-M. Impact of multiple cesarean deliveries on maternal morbidity: a systematic review. Am J Obstet Gynecol. 2011;205:262. e1-8

10. van Bogaert L-J. Mode of delivery after one cesarean section. Int J Gynaecol Obstet. 2004:87:9-13.

11. Barber EL, Lundsberg LS, Belanger K, Pettker CM, Funai EF, Illuzzi JL. Indications contributing to the increasing cesarean delivery rate. Obstet Gynecol. 2011;118:29-38.

12. Tulandi T, Agdi M, Zarei A, Miner L, Sikirica V. Adhesion development and morbidity after repeat cesarean delivery. Am J Obstet Gynecol. 2009;201:56. e1-6

13. Silver RM, Landon MB, Rouse DJ, Leveno KJ, Spong CY, Thom EA, et al. Maternal morbidity associated with multiple repeat cesarean deliveries. Obstet Gynecol. 2006;107:1226-32.

14. van Roosmalen J, van den Akker T. Safety concerns for caesarean section. BJOG. 2014;121:909-10.

15. van den Beukel BA, de Ree $R$, van Leuven S, Bakkum EA, Strik C, van Goor H, et al. Surgical treatment of adhesion-related chronic abdominal and pelvic pain after gynaecological and general surgery: a systematic review and meta-analysis. Hum Reprod Update. 2017;23:276-88.

16. Sbarra M, Boyd M, Dardarian TS. Complications due to adhesion formation following cesarean sections: a review of deliveries in three cases. Fertil Steril. 2009;92:394.e13-394.e16.

17. von Elm E, Altman DG, Egger M, Pocock SJ, Gøtzsche PC, Vandenbroucke JP. The Strengthening the Reporting of Observational Studies in Epidemiology (STROBE)statement: guidelines for reporting observational studies. J Clin Epidemiol. 2008;61:344-9.

18. Kasiulevičius V, Šapoka V, Filipavičiūtè R. Sample size calculation in epidemiological studies. Gerontologija. 2006;7:225-31.

19. Lumbiganon P, Laopaiboon M, Gülmezoglu AM, Souza JP, Taneepanichskul S, Ruyan P, et al. Method of delivery and pregnancy outcomes in Asia: the WHO global survey on maternal and perinatal health 2007-08. Lancet. 2010;375:490-9.

20. Okabayashi K, Ashrafian H, Zacharakis E, Hasegawa H, Kitagawa Y, Athanasiou T, et al. Adhesions after abdominal surgery: a systematic review of the incidence, distribution and severity. Surg Today. 2014;44:405-20.

21. Moro F, Mavrelos D, Pateman K, Holland T, Hoo WL, Jurkovic D. Prevalence of pelvic adhesions on ultrasound examination in women with a history of Cesarean section. Ultrasound Obstet Gynecol. 2015;45:223-8.

22. Zia S, Rafique M. Intra-operative complications increase with successive number of cesarean sections: Myth or fact? Obstet Gynecol Sci. 2014;57:187-92.

23. Nisenblat V, Barak S, Griness OB, Degani S, Ohel G, Gonen R. Maternal complications associated with multiple cesarean deliveries. Obstet Gynecol. 2006;108:21-6.

24. Walfisch A, Beloosesky R, Shrim A, Hallak M. Adhesion prevention after cesarean delivery: evidence, and lack of it. Am J Obstet Gynecol. 2014;211: $446-52$.
25. Choo S, Perry H, Hesse AAJ, Abantanga F, Sory E, Osen H, et al. Assessment of capacity for surgery, obstetrics and anaesthesia in 17 Ghanaian hospitals using a WHO assessment tool. Tropical Med Int Health. 2010;15:1109-15.

26. Kwawukume EY. Caesarean section in developing countries. Best Pract Res Clin Obstet Gynaecol. 2001;15:165-78.

27. Mathai M1, Hofmeyr GJ, Mathai NE. Abdominal surgical incisions for caesarean section. Cochrane Database Syst Rev. 2013;CD004453.v. doi:10. 1002/14651858.CD004453.pub3.

28. Killian CA, Graffunder EM, Vinciguerra TJ, Venezia RA. Risk factors for surgical-site infections following cesarean section. Infect Control Hosp Epidemiol. 2001;22:613-7.

29. Stevens GA, Finucane MM, De-Regil LM, Paciorek CJ, Flaxman SR, Branca F, et al. Global, regional, and national trends in haemoglobin concentration and prevalence of total and severe anaemia in children and pregnant and non-pregnant women for 1995-2011: a systematic analysis of populationrepresentative data. Lancet Glob Heal. 2013;1:e16-25.

30. CORONIS Collaborative Group, Abalos E, Addo V, Brocklehurst P, El Sheikh M, Farrell B, et al. Caesarean section surgical techniques (CORONIS): a fractional, factorial, unmasked, randomised controlled trial. Lancet. 2013;382:234-48.

31. CORONIS Collaborative Group. Caesarean section surgical techniques: 3 year follow-up of the CORONIS fractional, factorial, unmasked, randomised controlled trial. Lancet. 2016;388:62-72.

32. Arung W, Meurisse $M$, Detry O. Pathophysiology and prevention of postoperative peritoneal adhesions. World J Gastroenterol. 2011;17:4545-53.

33. ten Broek RPG, Stommel MWJ, Strik C, van Laarhoven CJHM, Keus F, van Goor $\mathrm{H}$. Benefits and harms of adhesion barriers for abdominal surgery: a systematic review and meta-analysis. Lancet. 2014;383:48-59.

34. Hindocha A, Beere L, Dias S, Watson A, Ahmad G. Adhesion prevention agents for gynaecological surgery: an overview of Cochrane reviews. Cochrane Database Syst Rev. 2015;1:CD011254.

35. Meara JG, Leather AJM, Hagander L, Alkire BC, Alonso N, Ameh EA, et al. Global Surgery 2030: evidence and solutions for achieving health, welfare, and economic development. Lancet. 2015:386:569-624.

\section{Submit your next manuscript to BioMed Central and we will help you at every step:}

- We accept pre-submission inquiries

- Our selector tool helps you to find the most relevant journal

- We provide round the clock customer support

- Convenient online submission

- Thorough peer review

- Inclusion in PubMed and all major indexing services

- Maximum visibility for your research

Submit your manuscript at www.biomedcentral.com/submit
) Biomed Central 